\title{
Solvent Extraction Characterization on Injection Molding of Mg Alloy
}

\author{
Nooraizedfiza Zainon ${ }^{1,2, *}$, Salmah Husseinshah ${ }^{1}$, Mohd Afian $\mathrm{Omar}^{3}$, and Marina \\ Marzuki $^{2}$ \\ ${ }^{1}$ Material Engineering School, Universiti Malaysia Perlis, Malaysia \\ ${ }^{2}$ Manufacturing Engineering School, Universiti Malaysia Perlis, Malaysia \\ ${ }^{3}$ Advance Materials Research Centre (AMREC), SIRIM Bhd., Kulim Hi-Tech Park, Kedah, Malaysia
}

\begin{abstract}
The effect of the leaching time and temperature on the solvent debinding process of $\mathrm{Mg}$ metal injection molding (MIM) green part has been investigated. In this study, both soluble binder, paraffin wax and stearic acid molecules were removed from the Mg MIM green part by immersing compact parts in heptane solution. Then, the solvent debinding rate has been investigated under the conditions of different leaching time and temperature. The weight loss percentages of paraffin wax and stearic acid were calculated and the pores structure was analyzed by scanning electron micrograph. The efficient diffusivity and activation energy of the soluble binder have also been studied. Result shows that the removal of soluble binder at high temperature is the fastest, but there are defects observed on the Mg MIM body. It was found that the total amount of binder removal was $68.24 \mathrm{wt.} \%, 75.56 \mathrm{wt} . \%$, and $84.92 \mathrm{wt.} \%$ for leaching temperature of $40{ }^{\circ} \mathrm{C}, 60^{\circ} \mathrm{C}$, and $80^{\circ} \mathrm{C}$, respectively. The remaining binder will be removed during first cycle of sintering process.
\end{abstract}

\section{Introduction}

Solvent extraction is extensively employed with wax-polymer binder system. To allow handling after extraction process, the wax and polymer should be insoluble in each other. The solvent debinding can be accomplished by immersion in liquid solvent at low temperature and pressure (immersion debinding), by immersion in supercritical solvent at high temperature and pressure (supercritical debinding, or by contacting with saturated vapor of a liquid solvent vapor condensate on the surface of the specimens forming in a liquid film that extracts the soluble component of the binder [1]. Inadequate binder removal will lead to part defect such as bloating, blistering, surface cracking and large internal voids [2-3]. Solvent extraction is extensively employed with wax-polymer binder system. To allow handling after extraction process, the wax and polymer should be insoluble in each other. The solvent debinding can be accomplished by immersion in liquid solvent at low

\footnotetext{
* Corresponding author: nooraizedfiza@unimap.edu.my
} 
temperature and pressure (immersion debinding), by immersion in supercritical solvent at high temperature and pressure (supercritical debinding, or by contacting with saturated vapor of a liquid solvent vapor condensate on the surface of the specimens forming in a liquid film that extracts the soluble component of the binder [4].

Several researchers had conducted a study on the solvent debinding with different influencing condition. Onbattuvelli et al. studied the effects of nanoparticle addition on the debinding of two different materials which is injection molded aluminum nitride (AIN) [5] and also silicon carbide ( $\mathrm{SiC})[6]$ compacts. The experiments varying the solvent debinding condition were performed on microscale and micro-nanoscale of injection molded compacts. The result shows that micro-nanoscale compacts has a slower solvent extraction of binder component compared to microscale compacts. Zaky et al., [7] studied on the debinding behavior of four different characteristics of paraffin wax. Data reveal that the binder system consisting $35 \mathrm{wt} . \%$ ethylene vinyl acetate, $62 \mathrm{wt} . \%$ of heavy paraffin wax, and $3 \mathrm{wt} . \%$ stearic acid which extracted at $40 \mathrm{C}$ for 5hours in the cyclohexane solvent, provides an excellent wax-based binder system. Previously, Zaky [8] proved that the higher solubility of $n$-hexane enhances the debinding rate. The efficiency diffusivity is proportional to leaching temperature/solvent viscosity. Subuki [9] studied on the debinding characteristics of the $316 \mathrm{~L}$ stainless steel compacts with palm stearin as a wax-based binder system. The result shows that the binder will be removed rapidly for higher powder loading which presumably reflecting in reduction of binder. Ani et al. [10] studied on debinding process involving two stages which focuses for ceramic powder. They found that temperature and immersion time significantly affect binder weight loss during solvent debinding. Zaki et al. [11] successfully separate the paraffin wax grades by applying the solvent extraction technique at different extraction temperatures and different solvent feed ratios.

Kim compared the debinding kinetics between supercritical fluid (SCF) extraction and n-heptane solvent extraction the results proved that rapid debinding without defect formation was successfully performed by the injection molded ceramic bodies with skeleton pores of $68 \mathrm{~nm}$. The debinding rate of SCF extraction was 5 times higher than that of the n-heptane extraction. Severe defects appear for solvent when temperature is exceeding $318.5 \mathrm{~K}$. However, the debinding defects were invisible for SCF up to $338.5 \mathrm{~K}$ [12]. Oliveira et al. investigated the influence of specimen dimension and solvent temperature on solvent debinding process. The green specimen with different bulk surface area ratio $(\mathrm{As} / \mathrm{V})$ were maintained in hexane at 20,40 , and $60^{\circ} \mathrm{C}$. The results reveal that there are strong influences of both parameters on the debinding kinetics. Higher As/V ratio and temperature requires less time to debind [13]. Foudzi et al. investigated the effects of the rheological properties and debinding on the sintered part of the yttria stabilized zirconia. Solvent debinding was carried at the three temperature $\left(50,60,70^{\circ} \mathrm{C}\right)$ using heptane solution. A large porous region was clearly identified at $70^{\circ} \mathrm{C}$ compared with $50^{\circ} \mathrm{C}$. The powder loading of $41 \mathrm{vol} . \%$ debound at $60^{\circ} \mathrm{C}$ gave the best mechanical properties during the mechanical strength and hardness test with values of $417 \mathrm{MPa}$ and $876 \mathrm{HV}$, respectively [14].

In our previous study, has been reported the effect of shear rate and temperature on rheology of $\mathrm{Mg}$ metal injection molding feedstock with multicomponent binder [15]. The result shows that the best powder loading was 65 vol.\%. In this study, the heptane solution was used to dissolve paraffin wax and stearic acid. This study aims to investigate the effect of the leaching temperature and time on the debinding rate. The weight loss percentages of paraffin wax and stearic acid were calculated and the pores structure was analyzed by scanning electron micrograph. The efficient diffusivity and activation energy of the soluble binder will be also investigated. 


\section{Experimental}

The magnesium powder with $\mathrm{D}_{50}$ of $22 \mu \mathrm{m}$ supplied by MGH Industrial Co., Ltd, China was used. Multicomponent binder system comprising of paraffin wax (PW), high-density polyethylene (HDPE), and stearic acid (SA) obtained from Titan Polyethylene (M) Sdn. Bhd., Johor Bharu, Malaysia. 65 vol.\% of powder loading with 35 vol.\% multicomponent binder system (PW/HDPE/SA with fraction of 55/35/10) are used in this study. A Universal V4.0C TA Instruments DSC Q10 V8.2 Build 268 and Netzsch simultaneous TG/DTA analyzer (STA) model 409C were used to measure the melting point and decomposition temperature of the binders. Vertical MCP 100KSA injection molding machine manufactured by MCP, Germany was used to produce the molded green body. The solvent was heated by placing a glass container in a water bath manufactured by Tech-Lab Manufacturing. Heptane with molecular weight of $100 \mathrm{~g} / \mathrm{mol}$ was added to the glass container to completely cover the samples. The glass container was covered with a watch glass to prevent evaporation of the heptane. The melting point of the binders used as the indicator for the selection of solvent temperature. Melting point for paraffin wax and stearic acid were $59.4{ }^{\circ} \mathrm{C}$ and $62.2{ }^{\circ} \mathrm{C}$, respectively. The $\mathrm{Mg}$ sample were immersed into the solvent at different extraction temperature which is $40{ }^{\circ} \mathrm{C}, 60^{\circ} \mathrm{C}$, and $80{ }^{\circ} \mathrm{C}$ and at different periods of time ranging from 10 minutes to 300 minutes. The samples were placed at the center of the solvent bath and were removed at each time point for weight loss and gravimetric analysis. The leach specimens were dried in an oven at $\pm 45^{\circ} \mathrm{C}$ for 5 hours to completely remove the remaining heptane. The weight loss was determined by weighing dried samples. SEM was used to study the binder distribution and the development of pores resulting from the progressive removal of the paraffin wax and stearic acid during immersion in heptane. The fraction of the soluble binder remaining, F, can be calculated as Eq. 1.

$$
\mathrm{F}=1-\left[\left(w_{i}-w_{t}\right) / f_{i} w_{i}\right]
$$

where, $f_{i}$ is the initial weight fraction of the soluble binder, $w_{i}$ is the initial mass of the compact and $w_{t}$ is the mass of compact at immersion time, $\mathrm{t}$.

Solvent debinding is a two stage process consisting of dissolution and diffusion [11]. Initially, solvent dissolves the paraffin wax and stearic acid and forming a porous surface. The solvent then penetrates into the pores by capillary action. This is followed by diffusion of dissolved paraffin wax out of the green body. The process can be expressed as Eq. 2 [7].

$$
\operatorname{Ln}\left(\frac{1}{\mathrm{~F}}\right)=\frac{\operatorname{Det} \pi 2}{\psi 2}+\mathrm{K}
$$

where, $\mathrm{F}$ is the fraction of the remaining soluble, $\mathrm{D}_{\mathrm{e}}$ is the effective diffusivity of soluble binder and solvent, $\mathrm{t}$ is time, $\psi$ is shape factor and $\mathrm{K}$ represents the change in the mechanism controlling the debinding behavior. Injection molded green body for this study corresponds to shape factor, $\psi$ of 1.9716 . The shape factor is colume to surface area ratio and can be calculated using Eq. 3 .

$$
\Psi=\frac{\mathrm{HB}(2 \mathrm{~L})}{2(\mathrm{HB}+\mathrm{B}(2 \mathrm{~L})+(2 \mathrm{~L}) \mathrm{H})}
$$

where $2 \mathrm{~L}, \mathrm{H}$, and $\mathrm{B}$ are the length, thickness, and breadth of the component, respectively. 
The activation energy for the extraction of paraffin wax and stearic acid from the green molded part was expressed as equation 4 .

$$
\mathrm{D}_{\mathrm{e}}=\mathrm{D}_{\mathrm{o}} \exp (-\mathrm{Q} / \mathrm{RT})
$$

where, $\mathrm{Q}$ is the activation energy for the solvent extraction, $\mathrm{R}$ is the universal gas constant, $T$ is the temperature in kelvin, $D_{e}$ is the diffusion coefficient, and $D_{o}$ is the maximum diffusion coefficient at infinite temperature. By plotting the graph of effective diffusivity, $D_{e}$ against the $1 / T$, the activation energy can be acquired.

\section{Results and discussions}

The goal of solvent debinding is to take out the binder elements in a shortest time with the least impact on the green body. Fig. 1 shows the effect of temperature and time on the amount of binder extracted during solvent debinding. From Fig.1, the total amount of binder extracted increases by increasing the extraction time ranging from 10 minutes to 300 minutes. The temperature dramatically influences the extraction rate at the first 30 minutes. This is due to the diffusion distance for the heptane and soluble binder which is short in the early stage of the debinding. The results clearly demonstrated that the speed removal of the paraffin wax and stearic acid occurs at higher leaching temperature of $80{ }^{\circ} \mathrm{C}$. The total amount of binder removal was 68.24 wt.\%, 75.56 wt.\%, and 84.92 wt.\% for leaching temperature of $40{ }^{\circ} \mathrm{C}, 60{ }^{\circ} \mathrm{C}$, and $80{ }^{\circ} \mathrm{C}$, respectively. At the first 30 minutes, it was observed that the binder extraction is faster at leaching temperature of $80{ }^{\circ} \mathrm{C}$ compared to temperature of $40{ }^{\circ} \mathrm{C}$ and $60{ }^{\circ} \mathrm{C}$. This is due to high diffusivity resulted by the high temperature which finally increased debinding rate. However, too fast removal of paraffin wax and stearic acid result the molded part to distort and surface cracking. It was observed that leaching time at $40{ }^{\circ} \mathrm{C}$ and $60{ }^{\circ} \mathrm{C}$ provided a better shape retention compared to leach at $80^{\circ} \mathrm{C}$. This result indicates that leaching temperature of $60^{\circ} \mathrm{C}$ was the most appropriate for leaching temperature. Ani [10] reported that the diffusion process is influenced by the microstructure layout of injected parts. Binders cannot be totally removed in case of dead ends since the porous channel in microstructures does not intersect with others.

Fig. 2 shows the plots of $\ln (1 / \mathrm{F})$ as a function of immersion time for solvent extraction of paraffin wax and stearic acid at different temperature. Slope of the graph represents the effective diffusivity of dissolution and diffusion stages which occur during solvent extraction process for Mg MIM molded part. From the Fig. 3, two different slopes can be observed which are associated with dissolution and diffusion stages. $D_{e}$ of the soluble binder can be determined in both cases using equation 2 and summarize in Table $1 . \mathrm{D}_{\mathrm{e}}$ value at the dissolution stage is higher than the diffusion stage. As temperature increase, the $\mathrm{D}_{\mathrm{e}}$ increase at dissolution stage but no significant changes were recorded in diffusion stage. As a result, the dissolution stage is more efficient than diffusion when temperature increases. Similar result reported by Sotomayor et al. [16], in their study on debinding of ferritic and austenitic stainless steel. They reveal that the diffusion coefficient of paraffin wax during dissolution stage is almost 5.5 times higher than diffusion stage. 


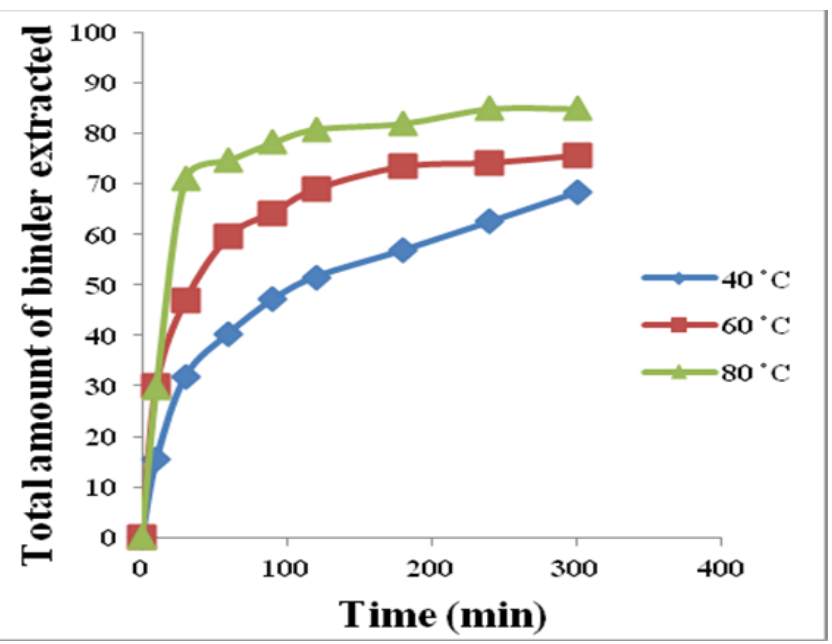

Fig. 1. Effect of extracted temperature and time on amount binder extracted of Mg MIM

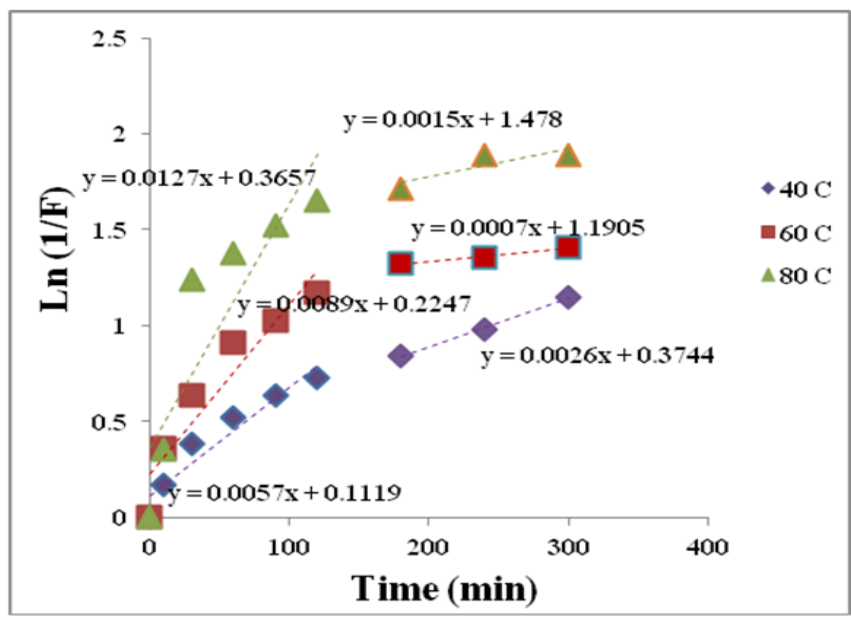

Fig. 2. Variation of $\ln (1 / \mathrm{F})$ with immersion time at $40{ }^{\circ} \mathrm{C}, 60^{\circ} \mathrm{C}$, and $80^{\circ} \mathrm{C}$

Table 1. Efficient diffusivity of the soluble binder at different temperature

\begin{tabular}{|c|c|c|}
\hline \multirow{2}{*}{ Temperature $\left({ }^{\circ} \mathrm{C}\right)$} & \multicolumn{2}{|c|}{ Efficient diffusivity (De) } \\
\cline { 2 - 3 } & Dissolution stage & Diffusion stage \\
\hline 40 & $2.2453 \mathrm{E}-5$ & $5.9085 \mathrm{E}-6$ \\
\hline 60 & $3.506 \mathrm{E}-5$ & $2.7573 \mathrm{E}-6$ \\
\hline 80 & $4.727 \mathrm{E}-5$ & $1.0241 \mathrm{E}-5$ \\
\hline
\end{tabular}

The activation energy can be calculated from the linear equation by plotting the graph of $\operatorname{Ln} D_{e}$ versus $1 / T$. According to Arrhenius equation as expressed in equation 4 , the $-Q / R$ 
value represented by the slope of the linear curve. The activation energy for extraction the soluble binder from magnesium molded part was estimated to be $17.1584 \mathrm{KJ} / \mathrm{mole}$. The activation energy of paraffin wax in heptane was $42 \pm 5 \mathrm{KJ} /$ mole [17]. This value was higher than the value obtained from this study. This is presumably due to different powder used and the present of the stearic acid in the soluble binder which may ease the extraction of the soluble binder form the system.

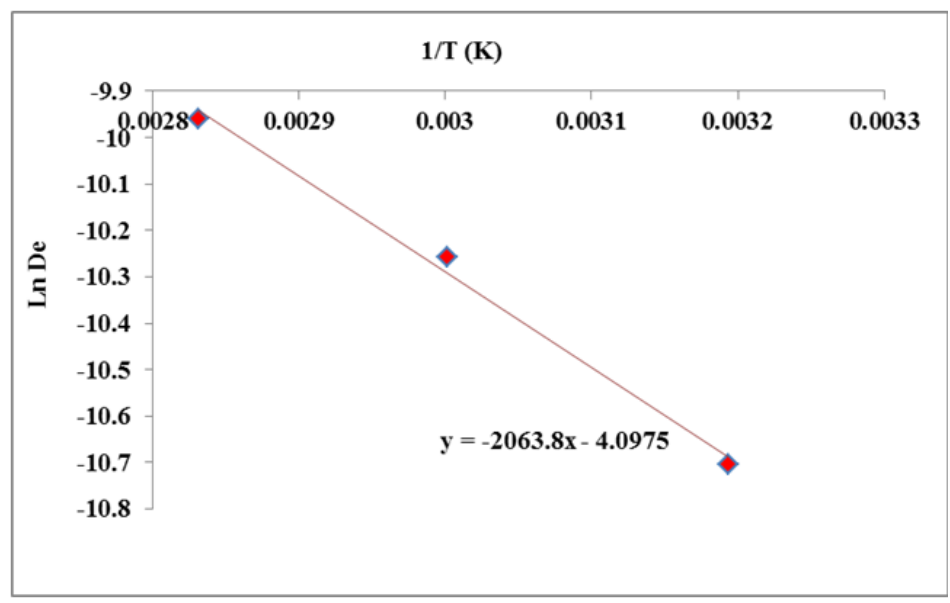

Fig. 3. The diffusion coefficient against $1 / \mathrm{T}$ of $\mathrm{Mg}$ MIM molded part

Fig.4 shows the microstructure of the molded part after solvent debinding at various times. Evaluation of the pore structure during solvent extraction at $60{ }^{\circ} \mathrm{C}$ was evaluated using SEM at fracture surface. At this temperature, the molded parts were fre free from defects. Fig.4 (a) to (d) shows the SEM of the samples at the center after 10, 60, 120, and 300 minutes leaching time, respectively. It reveals that pores with different sizes were formed. Some pore were within the binder represented by A in Fig.4 (a) and some were interparticle pores represented by B in Fig.4 (b), which indicate that all the binder component of PW, SA, and HDPE were mixed and interacted to a certain degree and that some PW and SA has been extracted. As the leaching time increases to 180 minutes as shown in Fig.4 (c), a large amount of binder leave spaces between the powder particles and increases the pore size which was labeled as C. While Fig.4 (d) shows the SEM of the sample after 300 minutes of leaching time. HDPE with irregular morphology was at the center region remained as interconnected capillary porosity inside the part which provided sufficient strength to hold the powder particles together prior to sintering process. 


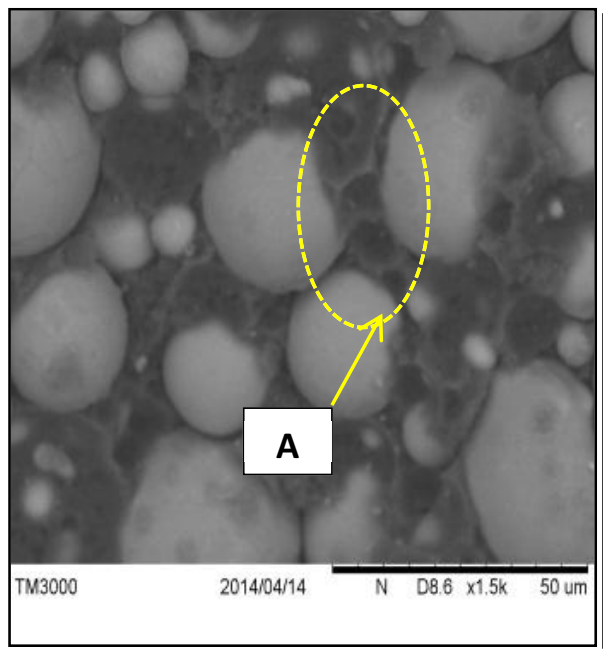

(a)

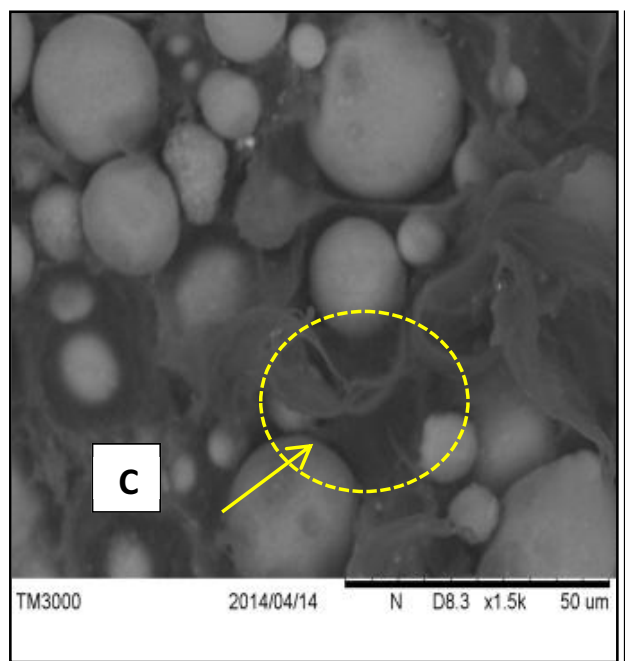

(c)

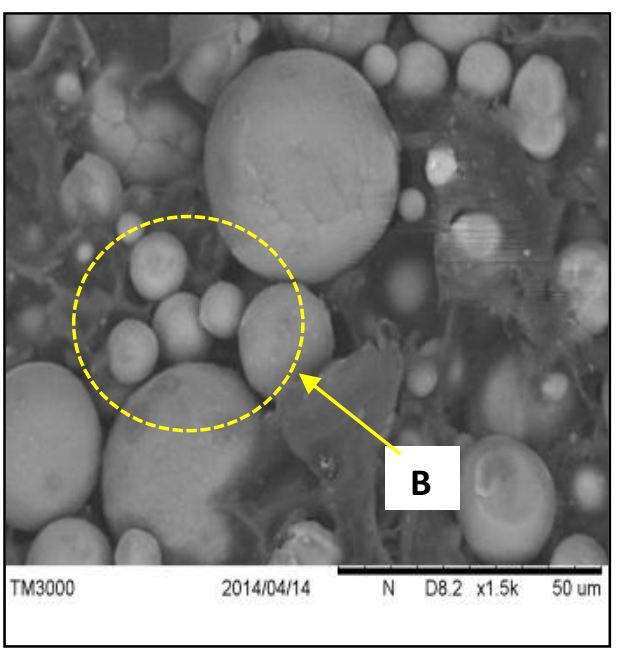

(b)

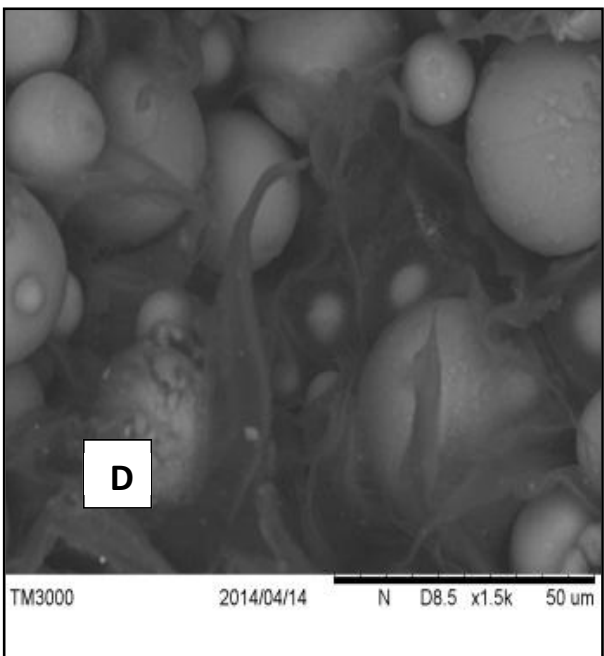

(d)

Fig. 4. The SEM on fracture surface Mg MIM molded part as a function of extraction time (a) 10 minutes, (b) 60 minutes, (c) 180 minutes, (d) 300 minutes.

\section{Conclusion}

The effect of leaching temperatures on the solvent debinding of paraffin wax and stearic acid in Mg MIM compact part were investigated. The result shows that the removal of soluble binder at high temperature is the fastest, but there are defects observed on the $\mathrm{Mg}$ MIM body. It was found that the total amount of binder removal was 68.24 wt. $\%, 75.56$ wt. $\%$, and 84.92 wt. $\%$ for leaching temperature of $40{ }^{\circ} \mathrm{C}, 60{ }^{\circ} \mathrm{C}$, and $80{ }^{\circ} \mathrm{C}$, respectively. Total amount of binder extracted has inverse relation to the diffusion coefficient of the soluble binder in the system with increasing time. The total amount of binder removed also increased, which reflects to the increasing of the diffusion distance and pore channels 
extended to the inner region of the body. The temperature gives the significant impact on the removal rate during dissolution stage but not to diffusion stage. The efficient diffusivity for dissolution stage was much higher than the diffusion stage for approximately 4 times. Result also shows that the efficient diffusivity at $80{ }^{\circ} \mathrm{C}$ was higher than $60{ }^{\circ} \mathrm{C}$ and $40{ }^{\circ} \mathrm{C}$ due to of high diffusivity. The activation energy for extracting the soluble binder from magnesium molded part was $17.1584 \mathrm{KJ} / \mathrm{mole}$. The SEM micrograph reveals more of pore developed after solvent debinding for 300 minutes.

This research was supported by Ministry of Higher Education (MOHE) for providing Fundamental Research Grant Scheme (FRGS) - No. 9003-00317.

\section{References}

1 R. M. German, A. Bose, Metal Powder Industries Federation (1997)

2 D.F. (Ed.) Heaney, Handbook of metal injection molding. Elsevier (2012)

3 V.A. Krauss, A.A.M. Oliveira, A.N. Klein, H.A. Al Qureshi, M.C. Fredel, J. Mater. Process Tech., 182, 268 (2007)

4 M.A. Omar, R. Ibrahim, M.I. Sidik, M. Mustapha, M. Mohamad, J. Mater. Process Tech., 140, 397 (2003)

5 V.P. Onbattuvelli, R.K. Enneti, S.J. Park, S.V. Atre, Int. J. Refract. Met. H., 36, 183 (2013)

6 V.P. Onbattuvelli, R. Chinn, R.K. Enneti, S.J. Park, S.V. Atre, Ceram. Int., 40, 13861 (2014)

7 M.T. Zaky, F.S. Soliman, A.S. Farag, J. Mater. Process. Tech., 209, 5981 (2009)

8 J. Zaki, J.P. Mitchell, Curr. Dir. Psychol. Sci., 22, 466 (2013)

9 I. Subuki, Injection Moulding of 316L Stainless Steel Powder Using Palm Stearin Based Binder System (Ph.D. Dissertation, Universiti Teknologi Mara, Malaysia, 2010).

10 S.M. Ani, A. Muchtar, N. Muhamad, J.A. Ghani, Ceram. Int., 40, 2819 (2014)

11 M.T. Zaky, N.H. Mohamed, A.S. Farag, Fuel Process Technol., 92 , 2024 (2011)

12 S.W. Kim, J. Supercrit. Fluid., 51, 339 (2010)

13 R.C.B. Oliveira, V. Soldi, M.C. Fredel, A.T.N. Pires, J. Mater. Process. Tech., 160, 213(2005)

14 F.M. Foudzi, N. Muhammad, A.B. Sulong, H. Zakaria, Ceram. Int., 39, 2665 (2013)

15 Z. Nooraizedfiza, H. Salmah, M.A. Omar, International Review of Mechanical Engineering, 7, 1378(2013)

16 M.E. Sotomayor, A. Varez, B. Lavenfeld, Powder Technol., 200, 30 (2010)

17 R.K. Enneti, T.S. Shivashankar, S.J. Park, R.M. German, S.V. Atre, Powder Technol, 228, 14(2012) 